\title{
Bacillus beijingensis sp. nov. and Bacillus ginsengi sp. nov., isolated from ginseng root
}

\author{
Correspondence \\ Wei Song \\ songwei@mail.cnu.edu.cn
}

\author{
Fubin Qiu, ${ }^{1,2}+$ Xiaoxia Zhang, ${ }^{1,3}$ † Lin Liu, ${ }^{1}$ Lei Sun, ${ }^{4}$ Peter Schumann ${ }^{5}$ \\ and Wei Song ${ }^{1}$
}

\author{
${ }^{1}$ College of Life Sciences, Capital Normal University, Beijing 100048, PR China \\ ${ }^{2}$ College of Public Health, Shanxi Medical University, Taiyuan 030001, PR China \\ ${ }^{3}$ Agricultural Cultural Collection of China, Institute of Agricultural Resources and Regional Planning, \\ Chinese Academy of Agricultural Sciences, Beijing 100081, PR China \\ ${ }^{4}$ College of Life Sciences, Hebei University, Baoding 071002, PR China \\ ${ }^{5} \mathrm{DSMZ}$ - Deutsche Sammlung von Mikroorganismen und Zellkulturen GmbH, Inhoffenstraße 7B, \\ 38124 Braunschweig, Germany
}

\begin{abstract}
Four alkaligenous, moderately halotolerant strains, designated ge09, ge $10^{\top}, \mathrm{ge}^{\top} 4^{\top}$ and ge15, were isolated from the internal tissue of ginseng root and their taxonomic positions were investigated by using a polyphasic approach. Cells of the four strains were Gram-positivestaining, non-motile, short rods. Phylogenetic analysis based on 16S rRNA gene sequences showed that strains ge09 and ge $10^{\top}$ formed one cluster and strains ge $14^{\top}$ and ge 15 formed another separate cluster within the genus Bacillus. 16S rRNA gene sequence similarities with type strains of other Bacillus species were less than $97 \%$. Levels of DNA-DNA relatedness among the four strains showed that strains ge09 and ge $10^{\top}$ and strains ge $14^{\top}$ and ge15 belonged to two separate species; the mean level of DNA-DNA relatedness between ge $10^{\top}$ and ge $14^{\top}$ was only $28.7 \%$. Their phenotypic and physiological properties supported the view that the two strains represent two different novel species of the genus Bacillus. The DNA G+C contents of strains ge $10^{\top}$ and ge $14^{\top}$ were 49.9 and 49.6 mol\%, respectively. Strains ge $10^{\top}$ and ge $14^{\top}$ showed the peptidoglycan type A4 $\alpha$ L-Lys-D-Glu. The lipids present in strains ge $10^{\top}$ and ge $14^{\top}$ were diphosphatidylglycerol, phosphatidylglycerol, a minor amount of phosphatidylcholine and two unknown phospholipids. Their predominant respiratory quinone was MK-7. The fatty acid profiles of the four novel strains contained large quantities of branched and saturated fatty acids. The predominant cellular fatty acids were iso- $\mathrm{C}_{15: 0}(42.5 \%)$, anteiso- $\mathrm{C}_{15: 0}(22.2 \%)$, anteiso$\mathrm{C}_{17: 0}(7.3 \%)$ and $\mathrm{C}_{16: 1} \omega 7 \mathrm{c}$ alcohol $(5.7 \%)$ in ge $10^{\top}$ and iso- $\mathrm{C}_{15: 0}(50.7 \%)$ and anteiso- $\mathrm{C}_{15: 0}$ $(20.1 \%)$ in $g e 14^{\top}$. On the basis of their phenotypic properties and phylogenetic distinctiveness, two novel species of the genus Bacillus are proposed, Bacillus beijingensis sp. nov. (type strain ge10 ${ }^{\top}=\mathrm{DSM} 19037^{\top}=$ CGMCC $1.6762^{\top}$ ) and Bacillus ginsengi sp. nov. (type strain ge $14^{\top}$ $=\operatorname{DSM} 19038^{\top}=$ CGMCC $1.6763^{\top}$ ).
\end{abstract}

The genus Bacillus contains aerobic or facultatively anaerobic, Gram-positive, sporulating, rod-shaped bacteria that are ubiquitous in nature. Bacillus species have a wide

†These authors contributed equally to this work.

Abbreviations: $\mathrm{ddH}_{2} \mathrm{O}$, double-distilled water; TEM, transmission electron microscopy.

The GenBank/EMBL/DDBJ accession numbers for the 16S rRNA gene sequences of strains ge09, ge $10^{\top}$, ge $14^{\top}$ and ge 15 are EF371373EF371376, respectively.

Carbon source utilization data and fatty acid profiles of strains ge09, ge $10^{\top}$, ge $14^{\top}$ and ge 15 are available as supplementary material with the online version of this paper. range of physiological adaptations that enable them to survive or thrive in harsh environments, ranging from desert sands and hot springs to Arctic soils and from freshwater to marine sediments. Some of them are alkaliphilic and halotolerant (Nielsen et al., 1995; Muntyan et al., 2002; Nogi et al., 2005; Pollock et al., 2007). In this paper, the taxonomic characterization of four novel bacterial strains (ge09, ge $10^{\mathrm{T}}$, ge $14^{\mathrm{T}}$ and ge15) isolated from the internal tissue of ginseng roots is reported. 16S rRNA gene sequencing, DNA-DNA relatedness studies and phenotypic testing showed that these four bacterial isolates represent two novel species of the genus Bacillus. 
Strains ge 09, ge $10^{\mathrm{T}}$, ge $14^{\mathrm{T}}$ and ge 15 were isolated originally on Luria-Bertani (LB) agar plates that had been seeded with a tissue suspension of ginseng roots and incubated at $28{ }^{\circ} \mathrm{C}$ for 3 days. Healthy 3 -year-old ginseng roots were sampled by the Institute of Medicinal Plant Development, Chinese Academy of Medical Sciences in Beijing, China. The root tissue suspension was prepared according to the following procedure (Qiu et al., 2007). Roots were separated from the soil, washed with tap water and surface-sterilized with $75 \%$ ethanol for $3 \mathrm{~min}$ and $2.6 \%$ sodium hypochlorite solution for 3-5 min followed by rinsing with sterile double-distilled water $\left(\mathrm{ddH}_{2} \mathrm{O}\right)$. The surface-sterilized root mass was pulverized in a ceramic mortar and diluted with sterile $\mathrm{ddH}_{2} \mathrm{O}$ using the standard dilution plating technique. Twenty-eight colonies formed on one of the plates. 16S rRNA gene sequence analysis revealed that four of them (strains ge09, ge10, ge14 and ge15) probably represented novel species of the genus Bacillus. The four strains were maintained on LB agar slants at $4{ }^{\circ} \mathrm{C}$ and as a glycerol suspensions $(20 \%$, v/v) at $-20{ }^{\circ} \mathrm{C}$. Biomass for chemotaxonomic and molecular systematic studies was prepared by growing the strains in shake flasks of LB broth [containing $\left(1^{-1}\right) 10 \mathrm{~g}$ casein peptone, $5 \mathrm{~g}$ yeast extract and $10 \mathrm{~g} \mathrm{NaCl} ; \mathrm{pH} 7.0]$ at $28{ }^{\circ} \mathrm{C}$ for 3-5 days. Cells were harvested by centrifugation, washed with $\mathrm{ddH}_{2} \mathrm{O}$ and freeze-dried before use in chemical studies.

Colonial properties of the isolates were observed on LB agar. Cell morphology was examined by light microscopy and transmission electron microscopy (TEM; Hitachi H600 ). For visualization of flagella, cells were mounted on copper grids, negatively stained with $1 \%(\mathrm{w} / \mathrm{v})$ uranyl acetate for $15 \mathrm{~min}$ and then subjected to TEM at $100 \mathrm{kV}$. To facilitate sporulation, $\mathrm{MnSO}_{4}\left(50 \mathrm{mg} \mathrm{l}^{-1}\right)$ was added to the medium. Spore formation was determined by staining with malachite green as described previously by Gerhardt et al. (1994). Strains were also observed by phase-contrast microscopy (DMRE; Leica) using an oil-immersion objective $(\times 100)$ to ascertain shape and motility. Gram staining was carried out using a standard procedure (Hucker \& Conn, 1923).

The catalase reaction, anaerobic growth, Voges-Proskauer test, resistance to lysozyme, growth in $\mathrm{NaCl}$, growth at $\mathrm{pH}$ 5.7, hydrolysis of starch, utilization of citrate and propionate, production of indole, deamination of phenylalanine, decomposition of casein and liquefaction of gelatin were examined by the methods of Gordon et al. (1973). Growth was tested at different temperatures $\left(4-50{ }^{\circ} \mathrm{C}\right)$ and $\mathrm{pH}(5.0-12.0)$ in LB medium. Utilization of a variety of substrates as sole carbon sources was tested using the Biolog system (Gram Positive Identification Test Panel; GP2 MicroPlate).

Purified peptidoglycan preparations were obtained after disruption of cells by shaking with glass beads and subsequent trypsin digestion according to the method of Schleifer (1985). Amino acids and peptides in cell-wall hydrolysates were analysed by two-dimensional ascending TLC on cellulose plates by using previously described solvent systems (Schleifer, 1985). The molar ratios of the amino acids were determined by GC and GC-MS of $\mathrm{N}$ heptafluorobutyryl amino acid isobutyl esters (MacKenzie, 1987). Cellular menaquinones were extracted and purified as described by Collins (1985) and analysed by HPLC (Wu et al., 1989). Polar lipids were extracted and analysed by two-dimensional TLC according to Tindall (1990). For determination of fatty acid composition, the four novel strains were cultivated on trypticase soy broth agar [containing $\left(\mathrm{l}^{-1}\right) 30 \mathrm{~g}$ trypticase soy broth and $15 \mathrm{~g}$ agar (Difco)] at $28{ }^{\circ} \mathrm{C}$ for $24 \mathrm{~h}$. Fatty acids were extracted, purified, methylated, identified and quantified by GC with the standard Microbial Identification system (MIDI) (Sasser, 1990; Kämpfer \& Kroppenstedt, 1996).

A loop of biomass was scraped off the agar plate, suspended in $20 \mu \mathrm{l} \mathrm{ddH}_{2} \mathrm{O}$ and lysed by boiling for $10 \mathrm{~min}$ and freezing for $5 \mathrm{~min}$. Following centrifugation, the supernatant was used as the template for PCR. The $16 \mathrm{~S}$ rRNA gene was amplified using the universal primers $27 \mathrm{~F}$ $\left(5^{\prime}\right.$-AGAGTTTGATCCTGGCTCAG-3') and 1492R (5'GGTTACCTTGTTACGACTT-3') (Lane, 1991). The amplified products were purified and cloned into vector Top10 (Tiangen) for sequence determination. Automated sequencing was performed by using an ABI BigDye Primer cycle sequencing ready reaction kit and an Applied Biosystems 3730 DNA sequencer. The sequencing primers were SP6 $\left(5^{\prime}\right.$-ATTTAGGTGACACTATAGAATAC- $\left.3^{\prime}\right)$ and T7 $\left(5^{\prime}\right.$ TAATACGACTCACTATAGGG-3'). The $16 \mathrm{~S}$ rRNA gene sequences of the four novel bacterial strains (ge09, $1551 \mathrm{bp}$; ge $^{\mathrm{T}}, 1512 \mathrm{bp}$; ge $14^{\mathrm{T}}, 1512 \mathrm{bp}$; ge15, $1552 \mathrm{bp}$ ) and those of other Bacillus species retrieved from GenBank were aligned using the program CLUSTAL_X v. 1.8 (Thompson et al., 1997). Three tree-making algorithms, namely the neighbour-joining (Saitou \& Nei, 1987), maximumparsimony (Eck \& Dayhoff, 1966; Fitch, 1971) and minimum evolution (Rzhetsky \& Nei, 1992) methods from the MEGA4 package (Tamura, et al., 2007), were used to infer phylogenetic evolutionary trees.

Preparation of genomic DNA was carried out according to the method of Marmur (1961). The DNA G + C content was determined using the thermal denaturation method (Marmur \& Doty, 1962) with Escherichia coli K-12 as a control. Levels of DNA-DNA relatedness among the four strains were determined by using the reassociation rate method at a hybridization temperature of $60{ }^{\circ} \mathrm{C}$ (Dong et al., 2000).

Comparisons with GenBank sequences revealed that the $16 \mathrm{~S}$ rRNA gene sequences of the four isolates did not match those of any known bacterium. The bacterium with the greatest pairwise similarity to strain ge $10^{\mathrm{T}}$ was the type strain of Bacillus pocheonensis (96.1\% $16 \mathrm{~S}$ rRNA gene sequence similarity), whereas the type strain of Bacillus fumarioli most closely matched strain ge $14^{\mathrm{T}} \quad(96.0 \%$ similarity). A comparative $16 \mathrm{~S}$ rRNA gene sequence 
similarity analysis revealed that the similarities among strains ge 09, ge $10^{\mathrm{T}}$, ge $14^{\mathrm{T}}$ and ge 15 were more than $98 \%$. The level of DNA-DNA relatedness between ge09 and ge $10^{\mathrm{T}}$ was $86.4 \%$ and that between ge $14^{\mathrm{T}}$ and ge15 was $70.7 \%$. The mean level of DNA-DNA relatedness between strains ge $10^{\mathrm{T}}$ and ge $14^{\mathrm{T}}(28.7 \%)$ was low enough to distinguish these two strains at the species level. A phylogenetic tree (Fig. 1) constructed using the neighbour-joining method suggested that strains ge09, ge $10^{\mathrm{T}}$, ge $14^{\mathrm{T}}$ and ge15 are members of the genus Bacillus, representing two distinct species. The phylogenetic trees inferred by maximum-parsimony and the minimum evolution method showed relationships similar to those presented in Fig. 1.

Morphological, cultural, physiological and biochemical characteristics of strains ge 09, ge $10^{\mathrm{T}}$, ge $14^{\mathrm{T}}$ and ge 15 are given in the species descriptions and in Table 1 and Supplementary Table S1 (available in IJSEM Online). Endospores were not observed in the novel isolates; this has also been found in some other bacilli, e.g. endospore formation has not been detected in Bacillus foraminis (Tiago et al., 2006) or Bacillus thermoamylovorans (Combet-Blanc et al., 1995). Strains ge $10^{\mathrm{T}}$ and ge $14^{\mathrm{T}}$ both showed peptidoglycan type A4 $\alpha$ L-Lys-D-Glu (A11.33 according to http://www.dsmz.de/microorganisms/main. php?content_id=35). In the case of strain ge $14^{\mathrm{T}}$, a small portion of D-Glu in the interpeptide bridge was replaced by D-Asp. The lipids present in strains ge $10^{\mathrm{T}}$ and ge $14^{\mathrm{T}}$ were diphosphatidylglycerol, phosphatidylglycerol, a minor amount of phosphatidylcholine and two unknown phospholipids.

Strain ge $14^{\mathrm{T}}$ grew only slowly on LB agar when compared with the other strains. Capsules around the cells of strain ge $14^{\mathrm{T}}$ that could not be detected in the other strains were observed by light and electron microscopy. In addition, the four novel strains were alkaligenous when cultivated in LB medium. The $\mathrm{pH}$ of medium increased to more than 8.0 after inoculation with the novel strains. MK-7 was the major menaquinone component, which is in agreement with the description of members of the genus Bacillus. The bacterial isolates were tested with the Biolog system (Gram Positive Identification Test Panel: GP2 MicroPlate) to assay their utilization of carbon sources (see Supplementary Table S1). The fatty acid profiles of the isolates were also compared (Supplementary Table S2). As with related Bacillus species, the fatty acid profiles of the four novel strains contained large quantities of branched and saturated fatty acids, especially iso- $\mathrm{C}_{15: 0}$ and anteiso- $\mathrm{C}_{15: 0}$.

According to their biochemical characteristics and cellular fatty acid profiles, it was demonstrated that the four isolates represent two different species; this was confirmed by the results of $16 \mathrm{~S}$ rRNA gene sequence comparisons and DNA-DNA hybridization data. Although a comparative 16S rRNA gene similarity analysis revealed that strain ge $10^{\mathrm{T}}$ was most closely related to strain ge $14^{\mathrm{T}}(98.49 \%)$, DNA-DNA hybridization results supported species differentiation of the two strains. There are many examples of Bacillus species having pairwise sequence similarities of $>98.5 \%$ (Ko et al., 2006), but with DNA-DNA relatedness values far below the $70 \%$ threshold for delineation of species (Wayne et al., 1987).

On the basis of the above biochemical data, cellular fatty acid compositions and molecular phylogenetic results, strains ge $10^{\mathrm{T}}$ and ge $14^{\mathrm{T}}$ represent two novel species of Bacillus, for which the names Bacillus beijingensis sp. nov. and Bacillus ginsengi sp. nov., respectively, are proposed.

\section{Description of Bacillus beijingensis sp. nov.}

Bacillus beijingensis (bei.jing.en'sis. N.L. masc. adj. beijingensis of Beijing, where the type strain was isolated).

Cells are alkaligenous, Gram-positive-staining, strictly aerobic, non-motile (non-flagellated), short rods to almost spherical in shape $(1.0-1.5 \times 0.5-0.8 \mu \mathrm{m})$. Endospores are not observed on $\mathrm{LB}$ agar supplemented with $\mathrm{MnSO}_{4}$. Cells are not killed by heating at $80{ }^{\circ} \mathrm{C}$ for $10 \mathrm{~min}$. After $24-48 \mathrm{~h}$ growth on LB agar, colonies are up to $3-7 \mathrm{~mm}$ in diameter, circular and raised, with entire edges and an off-white to

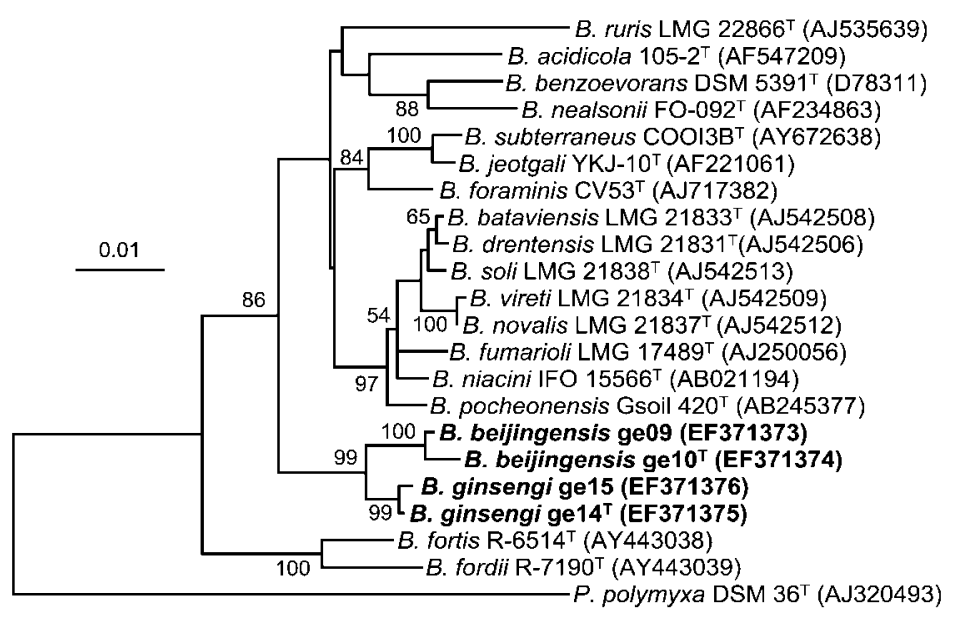

Fig. 1. Phylogenetic tree showing the relationships of the novel strains to related species within the genus Bacillus. The tree, based on an alignment of almost-complete 16S rRNA gene sequences, was constructed using the neighbour-joining method (Saitou \& Nei, 1987). The sequence of Paenibacillus polymyxa DSM $36^{\top}$ was used as an outgroup. Numbers at nodes indicate bootstrap support (\%) based on neighbour-joining analysis of 1000 resampled datasets (Felsenstein, 1985). Bar, 0.01 substitutions per nucleotide position. 
Table 1. Differential characteristic of strains ge09, ge $10^{\top}$, ge $14^{\top}$ and ge15 and phylogenetically related species of the genus Bacillus

Taxa: 1, strain ge09; 2, strain ge $10^{\mathrm{T}} ; 3$, strain ge $14^{\mathrm{T}} ; 4$, strain ge 15; 5, B. pocheonensis (data from Ten et al., 2007); 6, B. niacini (Nagel \& Andreesen, 1991); 7, B. fumarioli (Logan et al., 2000). +, Positive or present; (+), weakly positive; v, variable; -, negative or absent; NR, not reported.

\begin{tabular}{|c|c|c|c|c|c|c|c|}
\hline Characteristic & 1 & 2 & 3 & 4 & 5 & 6 & 7 \\
\hline Gram stain & + & + & + & + & + & $\mathrm{V}$ & + \\
\hline Motility & - & - & - & - & - & - & + \\
\hline Anaerobic growth & - & - & - & - & - & $(+)$ & - \\
\hline Optimum growth temperature $\left({ }^{\circ} \mathrm{C}\right)$ & 30 & 30 & 30 & 30 & 25 & 30 & 50 \\
\hline Growth at $50{ }^{\circ} \mathrm{C}$ & - & - & - & - & - & - & + \\
\hline pH 5.7 & $(+)$ & + & - & - & + & NR & + \\
\hline Voges-Proskauer test & - & - & - & - & $(+)$ & - & + \\
\hline \multicolumn{8}{|l|}{ Hydrolysis of: } \\
\hline Casein & + & + & - & + & - & - & - \\
\hline Gelatin & + & + & $(+)$ & + & - & + & + \\
\hline Aesculin & + & + & - & + & + & + & - \\
\hline Arginine dihydrolase & - & + & - & + & - & NR & - \\
\hline $\mathrm{NaCl}$ tolerance $(\%, \mathrm{w} / \mathrm{v})$ & $0-12$ & $0-12$ & $0-10$ & $0-12$ & $1-15$ & NR & NR \\
\hline Resistance to lysozyme & - & - & + & - & NR & NR & NR \\
\hline DNA G $+\mathrm{C}$ content $(\mathrm{mol} \%)$ & 50.6 & 49.9 & 49.6 & 50.6 & 44.9 & $37.0-39.0$ & 40.7 \\
\hline
\end{tabular}

yellow, opaque, glossy appearance. The optimum temperature for growth is $30{ }^{\circ} \mathrm{C}$; grows at $7-45{ }^{\circ} \mathrm{C}$. The $\mathrm{pH}$ range for growth is 5.5-11.0; optimum $\mathrm{pH}$ is 7.0-8.0. Can grow in $0-12 \% \mathrm{NaCl}$. Casein, gelatin and aesculin are hydrolysed; tests for catalase, oxidase and nitrate reduction are positive. Negative for utilization of citrate and propionate, hydrolysis of starch and Tween 80, phenylalanine deaminase, indole production and Voges-Proskauer and methyl red tests. Arginine dihydrolase activity is variable. Sensitive to lysozyme. The medium $\mathrm{pH}$ changes gradually from 7.0 to 8.5 during cultivation. Acetic acid, $\alpha$-ketovaleric acid, pyruvic acid methyl ester, pyruvic acid, L-alanine, L-alanyl glycine, L-glutamic acid, adenosine, 2'-deoxyadenosine, inosine, thymidine, L-malic acid, succinic acid monomethyl ester, succinamic acid, succinic acid and L-serine are used as sole carbon sources for energy and growth. Utilization of $\beta$-cyclodextrin, dextrin, glycogen, Tween 40 , $\mathrm{N}$-acetyl-D-glucosamine, L-arabinose, D-arabitol, D-fructose, myo-inositol, maltose, 3-methyl glucose, methyl $\alpha$-Dglucoside, methyl $\beta$-D-glucoside, methyl $\alpha$-D-mannoside, stachyose, turanose, xylitol, $\beta$-hydroxybutyric acid, $\alpha$ ketoglutaric acid, lactamide, D-lactic acid methyl ester, Dmalic acid, $\mathrm{N}$-acetyl-L-glutamic acid, L-alaninamide, Dalanine, glycyl L-glutamic acid, putrescine, glycerol and uridine as sole carbon sources is variable (Biolog). The major isoprenoid quinone is MK-7. The predominant cellular fatty acids are iso- $\mathrm{C}_{15: 0}$, anteiso- $\mathrm{C}_{15: 0}$, anteiso$\mathrm{C}_{17: 0}$, summed feature 4 (iso- $\mathrm{C}_{17: 1} \mathrm{I}$ and/or anteiso- $\mathrm{C}_{17: 1}$ B) and $\mathrm{C}_{16: 1} \omega 7 c$ alcohol.

The type strain is ge $10^{\mathrm{T}}\left(=\mathrm{DSM} 19037^{\mathrm{T}}=\mathrm{CGMCC}\right.$ $1.6762^{\mathrm{T}}$ ), isolated from the internal tissue of ginseng roots cultivated in Beijing, China. The DNA G $+\mathrm{C}$ content of strain ge $10^{\mathrm{T}}$ is $49.9 \mathrm{~mol} \%$. Strain ge09 is a second strain of the species.

\section{Description of Bacillus ginsengi sp. nov.}

Bacillus ginsengi (gin.sen'gi. N.L. gen. n. ginsengi of ginseng, the source of the type strain).

Cells are alkaligenous, Gram-positive-staining, strictly aerobic, non-motile (non-flagellated), short rods to almost spherical in shape $(1.1-1.5 \times 0.9-1.3 \mu \mathrm{m})$. Endospores are not observed on LB agar supplemented with $\mathrm{MnSO}_{4}$. Capsules are observed by light and electron microscopy. Cells are not killed by heating at $80{ }^{\circ} \mathrm{C}$ for $10 \mathrm{~min}$. After $24-48 \mathrm{~h}$ growth on LB agar, colonies are up to $2-3 \mathrm{~mm}$ in diameter, circular and raised, with entire edges and an offwhite to yellow, opaque, glossy appearance. Cells grow slowly on LB agar and in LB medium. Usually, it is necessary to cultivate cells for more than 5 days in shake flasks of LB broth at $28{ }^{\circ} \mathrm{C}$ to reach the concentration required for chemotaxonomic studies. Optimum growth temperature is $30{ }^{\circ} \mathrm{C}$; grows at $4-45^{\circ} \mathrm{C}$. The $\mathrm{pH}$ range for growth is 6.0-11.0; optimum $\mathrm{pH}$ is 7.0-8.0. Can grow in 0 $10 \% \mathrm{NaCl}$. Positive for catalase and oxidase activities, gelatin hydrolysis and nitrate reduction. Negative for hydrolysis of Tween 80 and starch, phenylalanine deaminase, indole production, Voges-Proskauer and methyl red tests and utilization of citrate and propionate. Variable for hydrolysis of casein and aesculin, arginine dihydrolase and lysozyme resistance. The medium $\mathrm{pH}$ changes gradually from 7.0 to 8.5 during cultivation. Acetic acid, $\alpha-$ ketovaleric acid, pyruvic acid methyl ester, pyruvic acid, L-alanine, L-alanyl glycine, L-glutamic acid, adenosine, 2'deoxyadenosine, inosine, thymidine, glycogen, $\mathrm{N}$-acetyl-Dglucosamine, $N$-acetyl- $\beta$-D-mannosamine, L-alaninamide, uridine, AMP, UMP and TMP are used as sole carbon sources for energy and growth. Variable (Biolog) for utilization of $\beta$-cyclodextrin, Tween $40, \mathrm{D}$-fructose, 
D-mannose, D-psicose, sedoheptulosan, $\beta$-hydroxybutyric acid, $\gamma$-hydroxybutyric acid, $\alpha$-ketoglutaric acid, D-lactic acid methyl ester, L-malic acid, succinic acid monomethyl ester, propionic acid, succinamic acid, succinic acid, $N$ acetyl-L-glutamic acid, D-alanine, L-asparagine, glycyl Lglutamic acid, L-serine, 2,3-butanediol and glycerol as sole carbon sources. The major isoprenoid quinone is MK-7. The predominant cellular fatty acids are iso- $\mathrm{C}_{15: 0}$, anteiso$\mathrm{C}_{15: 0}$, anteiso- $\mathrm{C}_{17: 0}$ and summed feature 4 (iso- $\mathrm{C}_{17: 1}$ I and/or anteiso- $\mathrm{C}_{17: 1} \mathrm{~B}$ ).

The type strain is ge $14^{\mathrm{T}}$ (=DSM $19038^{\mathrm{T}}=\mathrm{CGMCC}$ $\left.1.6763^{\mathrm{T}}\right)$, isolated from the internal tissue of ginseng roots cultivated in Beijing, China. The DNA G $+\mathrm{C}$ content of strain ge $14^{\mathrm{T}}$ is $49.6 \mathrm{~mol} \%$. Strain ge15 is a second strain of the species.

\section{Acknowledgements}

We are very grateful to Professor Wanlong Ding for offering ginseng samples. This work was supported by the National Natural Science Foundation of China (grants no. 30370032, 30770069), the Education Ministry Foundation of China (grant no. 20060028001) and the Natural Science Foundation of Shanxi (grant no. 2008012010-3).

\section{References}

Collins, M. D. (1985). Isoprenoid quinone analysis in classification and identification. In Chemical Methods in Bacterial Systematics, pp. 267-287. Edited by M. Goodfellow \& D. E. Minnikin. London: Academic Press.

Combet-Blanc, Y., Ollivier, B., Streicher, C., Patel, B. K., Dwivedi, P. P., Pot, B., Prensier, G. \& Garcia, J. L. (1995). Bacillus thermoamylovorans sp. nov., a moderately thermophilic and amylolytic bacterium. Int J Syst Bacteriol 45, 9-16.

Dong, X., Xin, Y., Jian, W., Liu, X. \& Ling, D. (2000). Bifidobacterium thermacidophilum sp. nov., isolated from an anerobic digester. Int $J$ Syst Evol Microbiol 50, 119-125.

Eck, R. V. \& Dayhoff, M. O. (1966). Atlas of Protein Sequence and Structure. Silver Springs, MD: National Biomedical Research Foundation.

Felsenstein, J. (1985). Confidence limits on phylogenies: an approach using the bootstrap. Evolution 39, 783-791.

Fitch, W. M. (1971). Toward defining the course of evolution: minimum change for a specific tree topology. Syst Zool 20, 406-416.

Gerhardt, P., Murray, R. G. E., Wood, W. A. \& Krieg, N. R. (editors) (1994). Methods for General and Molecular Bacteriology. Washington, DC: American Society for Microbiology.

Gordon, R. E., Haynes, W. C. \& Pang, C. H.-N. (1973). The Genus Bacillus. US Department of Agriculture Handbook no. 427. Washington, DC: Agricultural Research Service.

Hucker, G. J. \& Conn, H. J. (1923). Method of Gram staining N Y State Agric Exp Stn Tech Bull 93, 3-37.

Kämpfer, P. \& Kroppenstedt, R. M. (1996). Numerical analysis of fatty acid patterns of coryneform bacteria and related taxa. Can J Microbiol 42, 989-1005.

Ko, K. S., Oh, W. S., Lee, M. Y., Lee, J. H., Lee, H., Peck, K. R., Lee, N. Y. \& Song, J.-H. (2006). Bacillus infantis sp. nov. and Bacillus idriensis sp. nov., isolated from a patient with neonatal sepsis. Int $J$ Syst Evol Microbiol 56, 2541-2544.
Lane, D. J. (1991). 16S/23S rRNA sequencing. In Nucleic Acid Techniques in Bacterial Systematics, pp. 115-175. Edited by E. Stackebrandt \& M. Goodfellow. Chichester: Wiley.

Logan, N. A., Lebbe, L., Hoste, B., Goris, J., Forsyth, G., Heyndrickx, M., Murray, B. L., Syme, N., Wynn-Williams, D. D. \& De Vos, P. (2000). Aerobic endospore-forming bacteria from geothermal environments in northern Victoria Land, Antarctica, and Candlemas Island, South Sandwich archipelago, with the proposal of Bacillus fumarioli sp. nov. Int J Syst Evol Microbiol 50, 1741-1753.

MacKenzie, S. L. (1987). Gas chromatographic analysis of amino acids as the N-heptafluorobutyryl isobutyl esters. J Assoc Off Anal Chem 70, 151-160.

Marmur, J. (1961). A procedure for the isolation of deoxyribonucleic acid from microorganisms. J Mol Biol 3, 208-218.

Marmur, J. \& Doty, P. (1962). Determination of base composition of deoxyribonucleic acid from its thermal denaturation temperature. J Mol Biol 5, 109-118.

Muntyan, M. S., Tourova, T. P., Lysenko, A. M., Kolganova, T. V., Fritze, D. \& Skulachev, V. P. (2002). Molecular identification of alkaliphilic and halotolerant strain Bacillus sp. FTU as Bacillus pseudofirmus FTU. Extremophiles 6, 195-199.

Nagel, M. \& Andreesen, J. R. (1991). Bacillus niacini sp. nov., a nicotinate-metabolizing mesophile isolated from soil. Int $J$ Syst Bacteriol 41, 134-139.

Nielsen, P., Fritze, D. \& Priest, F. G. (1995). Phenetic diversity of alkaliphilic Bacillus strains: proposal for nine new species. Microbiology 141, 1745-1761.

Nogi, Y., Takami, H. \& Horikoshi, K. (2005). Characterization of alkaliphilic Bacillus strains used in industry: proposal of five novel species. Int J Syst Evol Microbiol 55, 2309-2315.

Pollock, J., Weber, K. A., Lack, J., Achenbach, L. A., Mormile, M. R. \& Coates, J. D. (2007). Alkaline iron(III) reduction by a novel alkaliphilic, halotolerant, Bacillus sp. isolated from salt flat sediments of Soap Lake. Appl Microbiol Biotechnol 77, 927-934.

Qiu, F., Huang, Y., Sun, L., Zhang, X., Liu, Z. \& Song, W. (2007). Leifsonia ginsengi sp. nov., isolated from ginseng root. Int J Syst Evol Microbiol 57, 405-408.

Rzhetsky, A. \& Nei, M. (1992). A simple method for estimating and testing minimum evolution trees. Mol Biol Evol 9, 945-967.

Saitou, N. \& Nei, M. (1987). The neighbor-joining method: a new method for reconstructing phylogenetic trees. Mol Biol Evol 4, 406425.

Sasser, M. (1990). Identification of bacteria by gas chromatography of cellular fatty acids, MIDI Technical Note 101. Newark, DE: MIDI Inc.

Schleifer, K. H. (1985). Analysis of the chemical composition and primary structure of murein. Methods Microbiol 18, 123-156.

Tamura, K., Dudley, J., Nei, M. \& Kumar, S. (2007). MEGA4: molecular evolutionary genetics analysis (MEGA) software version 4.0. Mol Biol Evol 24, 1596-1597.

Ten, L. N., Baek, S.-H., Im, W.-T., Larina, L. L., Lee, J.-S., Oh, H.-M. \& Lee, S.-T. (2007). Bacillus pocheonensis sp. nov., a moderately halotolerant, aerobic bacterium isolated from soil of a ginseng field. Int J Syst Evol Microbiol 57, 2532-2537.

Thompson, J. D., Gibson, T. J., Plewniak, F., Jeanmougin, F. \& Higgins, D. G. (1997). The CLUSTAL_X windows interface: flexible strategies for multiple sequence alignment aided by quality analysis tools. Nucleic Acids Res 25, 4876-4882.

Tiago, I., Pires, C., Mendes, V., Morais, P. V., da Costa, M. S. \& Veríssimo, A. (2006). Bacillus foraminis sp. nov., isolated from a nonsaline alkaline groundwater. Int J Syst Evol Microbiol 56, 2571-2574. 
Tindall, B. J. (1990). Lipid composition of Halobacterium lacusprofundi. FEMS Microbiol Lett 66, 199-202.

Wayne, L. G., Brenner, D. J., Colwell, R. R., Grimont, P. A. D., Kandler, O., Krichevsky, M. I., Moore, L. H., Moore, W. E. C., Murray, R. G. E. \& other authors (1987). International Committee on Systematic
Bacteriology. Report of the ad hoc committee on reconciliation of approaches to bacterial systematics. Int J Syst Bacteriol 37, 463-464.

Wu, C., Lu, X., Qin, M., Wang, Y. \& Ruan, J. (1989). Analysis of menaquinone compound in microbial cells by HPLC. Microbiology [English translation of Microbiology (Beijing)] 16, 176-178. 